
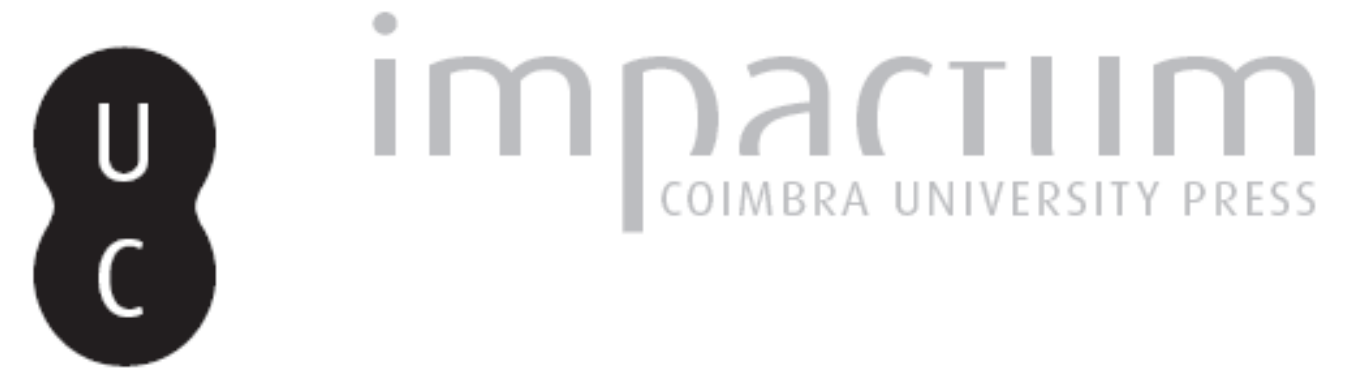

\title{
O império de um profeta sereno: ensaio de decifração do pensamento do padre António Vieira
}

Autor(es): $\quad$ Ribeiro, António Vítor Sanches Ferreira

Publicado por: Imprensa da Universidade de Coimbra

URL persistente:

URI:http://hdl.handle.net/10316.2/40958

DOI:

DOI:https://doi.org/10.14195/1645-2259_16_8

Accessed : $\quad$ 26-Apr-2023 10:51:32

A navegação consulta e descarregamento dos títulos inseridos nas Bibliotecas Digitais UC Digitalis, UC Pombalina e UC Impactum, pressupõem a aceitação plena e sem reservas dos Termos e Condições de Uso destas Bibliotecas Digitais, disponíveis em https://digitalis.uc.pt/pt-pt/termos.

Conforme exposto nos referidos Termos e Condições de Uso, o descarregamento de títulos de acesso restrito requer uma licença válida de autorização devendo o utilizador aceder ao(s) documento(s) a partir de um endereço de IP da instituição detentora da supramencionada licença.

Ao utilizador é apenas permitido o descarregamento para uso pessoal, pelo que o emprego do(s) título(s) descarregado(s) para outro fim, designadamente comercial, carece de autorização do respetivo autor ou editor da obra.

Na medida em que todas as obras da UC Digitalis se encontram protegidas pelo Código do Direito de Autor e Direitos Conexos e demais legislação aplicável, toda a cópia, parcial ou total, deste documento, nos casos em que é legalmente admitida, deverá conter ou fazer-se acompanhar por este aviso.

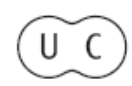




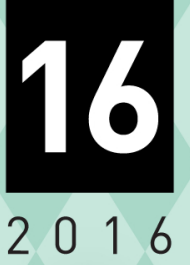

\section{Revista \\ de História \\ da Sociedade \\ e da \\ Cultura}




\title{
O império de um profeta sereno: ensaio de decifração do pensamento do padre António Vieira
}

\section{A serene prophet's empire: an essay on deciphering Father António Vieira's thought}

\author{
António Vítor Sanches Ferreira Ribeiro \\ Universide de Coimbra - CHSC; Universidade Católica Portuguesa - CEHR-UCP \\ avs.ribeiro@gmail.com
}

Texto recebido em / Text submitted on: 20.02.2016

Texto aprovado em / Text approved on: 09.06.2016

Resumo: O “Quinto Império” de António Vieira tem sido alvo de inúmeras interpretações. Contudo, estas têm-se restringido ao universo português e não têm em devida conta as influências externas exercidas sobre o jesuíta português. Simultaneamente, os aspetos mais exuberantes do seu pensamento, como a teoria da ressurreição de D. João IV, são olhados como uma mera curiosidade atribuível à idiossincrasia do seu espírito. Este artigo propõe-se reconstruir, a partir de documentação inédita, a lógica presente no pensamento de António Vieira, cujas origens podem ser atribuíveis ao milenarismo protestante inglês e holandês. Pretende-se ainda mostrar que a teoria da ressurreição do rei português se insere no interior dessa mesma lógica e resulta de uma técnica de interpretação das Escrituras bastante popular no mundo protestante. Finalmente, pretende-se também demonstrar que a sociedade portuguesa da época era bastante permeável a essa influência e que o caso de Vieira não foi o único.

Palavras-chave: Vieira, Inquisição, Menasseh, milenarismo, revolução inglesa.

Abstract: António Vieira's "Fifth Empire" has been the subject of numerous interpretations. However, these have remained restricted to the Portuguese world, and foreign influences exerted upon the Portuguese Jesuit have been neglected. Simultaneously, the more exuberant elements of Vieira's thought, such as the thesis of King John IV's resurrection, are usually dismissed as a simple curiosity caused by his spirit's idiosyncrasy. This paper aims to reconstruct the logic of Vieira's thought, based on unpublished sources whose origin may be traced to English and Dutch Protestant millenarianism. The author also intends to show that the Portuguese king's resurrection theory falls within this same logic and results in a form of interpreting the Scriptures that was popular in the Protestant world. Finally, it is intended to demonstrate that Vieira's contemporary Portuguese society was permeable to such influence and that Vieira's case was not an isolated one.

Keywords: Vieira, Inquisition, Menasseh, millenarianism, English revolution. 
$\mathrm{Na}$ sua obra $\mathrm{O}$ império colonial português, o historiador Charles Boxer estabelece uma comparação genérica e difusa entre o pensamento do Padre António Vieira e os acontecimentos revolucionários de meados do século XVII em Inglaterra:

Basta apenas recordarmos os ministros calvinistas do exército dos escoceses em Dunbar com o seu grito de batalha "Jesus e sem quartel" e o Major-General Thomas Harrison e os seus homens da Quinta Monarquia que acreditavam que a Inglaterra estava destinada a desempenhar o papel que Vieira atribuía a Portugal (Boxer 1977: 410).

De facto, é de notar a coincidência entre as noções de Quinto Império e de Quinta Monarquia, que bebem na mesma fonte: a interpretação dos livros de Daniel e do Apocalipse em chave tipológica e profética. Depois, a expetativa do regresso dos judeus a Inglaterra como condição para o cumprimento do Reino Universal de Cristo. Para além destas, há uma outra coincidência notável. Quando o líder do movimento, Thomas Harrison, foi executado, alguns dos seus seguidores desenvolveram um raciocínio que para eles era o mais lógico; como as suas expectativas ainda não haviam sido cumpridas, o Major-General teria necessariamente que ressuscitar.

Como se verá, a coincidência não é apenas formal. Neste texto procurarei demonstrar que o pensamento que enforma o Quinto Império do Padre Vieira resulta, em grande medida, da importação de uma forma exegética protestante. A outra influência, procurarei igualmente demonstrá-lo, vem da especificidade jesuítica.

Mas comece-se pela própria ideia de Quinto Império. Num artigo redigido em 1940, Joseph Ward Swain apresentou uma tese inovadora. Segundo este autor, a ideia de Quinto Império tinha sido desenvolvida no Oriente, ainda na Antiguidade, como forma de oposição ao império romano. Swain faz notar nesse artigo que a ideia da sucessão de quatro impérios é anterior ao próprio sonho de Daniel e aventa a possibilidade da origem persa deste último (Swain 1940).

Existe, na realidade, um fundo que remete para a cultura clássica na ideia de Quinto Império e no sonho de Nabucodonosor, interpretado por Daniel. A hierarquia dos metais e a ideia de regresso a um período de felicidade deixam entrever uma conceção cíclica do tempo. Talvez por isso, depois de mais de um milénio de relativo eclipse, a ideia aparecesse reativada pela recuperação da mundividência clássica, nos inícios do século XVI, na figura de um cardeal humanista fortemente inclinado para a exegese judaica. Egídio de Viterbo seria o responsável por uma síntese entre o esquema definido por Hesíodo das idades dos metais, assente num modelo de queda e restituição, 
e o mundo semita representado na profecia de Daniel (O’Malley 1968: 103; Reeves 1991). Para Egídio, Roma era o quarto império que deveria preceder a regeneração total da Igreja, a qual deveria voltar a um estado de inocência primitiva.

Paralelamente, teve lugar uma outra evolução nos alvores da época moderna: a emergência da exegese bíblica baseada numa interpretação figurativa ou tipológica. Nesta, os factos narrados nos textos sagrados são considerados como "figuras" que devem ser entendidas e descodificadas. Uma tal análise desvaloriza os factos em si e exalta a função de símbolo ou significante de um outro facto, oculto, que funciona como significado. Este processo deu origem a uma casta de profetas a que darei o nome de "serenos". António Vieira era um profeta sereno, no sentido em que não era acometido por visões, locuções e êxtases espetaculares, tão característicos da sua época.

A "figura" afirma-se com Tertuliano (sécs. II-III d. C.). Nasce aqui a ideia, que será central na exegese cristã posterior, das correspondências entre o Antigo e o Novo Testamentos. Ao mesmo tempo nasceram dois polos interpretativos, uma corrente que via esta figuração como representando acontecimentos históricos concretos, e a outra que atribuía à interpretação figurativa um sentido mais espiritual (Auerbach 1994: 31). A partir do século IV a interpretação figurativa atinge a plenitude em quase todos os autores da cristandade latina e a primeira corrente tornou-se preponderante.

Segundo Henri de Lubac, todo este sistema se completa e organiza no século XII com o abade cisterciense Joaquim de Fiore (1135-1202) (Lubac 1959: 521). Dividindo a História em três períodos e fazendo-os corresponder às três pessoas da Trindade, Pai, Filho e Espírito Santo, Joaquim integra esta relação especular entre o Antigo Testamento (idade do Pai) e o Novo Testamento (idade do Filho) num processo triádico que deveria concluir-se com o nascimento da terceira e derradeira época histórica, a idade do Espírito Santo. O Antigo e Novo Testamentos deveriam refletir-se através de acontecimentos "tipológicos" (Reeves 1993; Lubac 1981).

Num artigo publicado na American Historical Review, Jorge Cañizares-Esguerra colocou a questão da semelhança entre determinadas formas de milenarismo europeu existentes no espaço atlântico. Foi precisamente na questão da existência de uma tradição tipológica comum a todo o espaço europeu que este autor viu a razão de ser de um tal fenómeno. Contudo, Cañizares-Esguerra faz notar que a partir de uma determinada altura a tipologia se tornou uma forma exegética peculiar ao protestantismo (Cañizares-Esguerra 2007: 792).

Embora tenha frutificado principalmente no mundo protestante, esta tipologia profética parece ter tido início nos escritos de alguns jesuítas. Iden- 
tificado como a origem de toda esta viragem surge o jesuíta Francisco Ribera e a sua interpretação do Apocalipse (1592) (Armogathe 2001: 246). O continuador de Ribera seria um outro jesuíta, o flamengo Cornelius a Lapide.

Como o próprio referiu no seu processo inquisitorial, Cornelius foi uma fonte fundamental para Vieira no que diz respeito à interpretação do livro do Apocalipse. Cita-o, em particular, num ponto que parece ter perturbado os inquisidores: a destruição de Roma, identificada como a grande meretriz da Babilónia (Muhana 1995: 90).

Paralelamente à novidade trazida por Ribera e Cornelius, a exegese profética sofreria uma evolução em Inglaterra. Por volta de 1600 estabeleceu-se nesse país um núcleo de hebraístas encarregues de traduzir uma "versão autorizada” do Antigo Testamento. Por esta via, os académicos ingleses tiveram acesso à exegese judaica das Escrituras. A partir dessa altura os judeus começaram a ser vistos cada vez mais como uma peça fundamental para o cumprimento das profecias (Zakai 1997: 222-23). Assim, os exegetas ingleses começaram a ligar a destruição de Roma à conversão dos hebreus. Esta profetizada queda de Roma é um dos aspetos negligenciados do processo de Vieira e que o ligam a um pensamento apocalíptico estranho ao contexto português.

A evolução inglesa conheceria um desenvolvimento decisivo com a publicação em 1627 da obra-mestra de Joseph Mede (1586-1638). A obra era a Clavis Apocalyptica e pretendia lançar as bases de uma sistematização da exegese profética das Escrituras. Sintetizando um pouco a ideia, pode dizer-se que tentou criar uma ciência da profecia. Mede era, também, um profeta sereno.

Joseph Mede é o elo que faz a ligação entre a tradição figurativa inglesa e o padre António Vieira. Na Clavis Apocalyptica é apresentado um esquema de correspondências de natureza tipológica ligando o livro de Daniel ao livro do Apocalipse, ao mesmo tempo que projeta essas correspondências para o tempo futuro (Delumeau 1997: 269). Os pontos de contacto entre Vieira e Mede não podem, na minha opinião, ser atribuídos ao acaso.

Desde logo a ligação que faz entre Daniel e o Apocalipse, onde se funda a tese da Quinta Monarquia. Depois, o próprio título Clavis Apocalyptica, semelhante à Clavis Prophetarum redigida pelo jesuíta português alguns anos mais tarde. Ambas as obras têm o mesmo propósito, que é anunciado no nome: estabelecer uma chave interpretativa. Neste ponto é muito importante notar que Vieira tinha já retirado o título da sua obra Esperanças de Portugal de uma outra redigida por Menasseh Ben Israel com título semelhante, as Esperanças de Israel (Saraiva 1992: 101). 
A fundamentação geral que é fornecida na obra de Mede para justificar a sua expectativa messiânica é também a mesma de Vieira. Ambos referem que o conhecimento humano é cumulativo e que o mundo parece estar a chegar a uma maturidade anunciadora de uma nova era. Nesta perspetiva considera-se que Aristóteles, por mais ilustre que tenha sido, viveu na infância da humanidade (Popkin 1992: 106). Esta ideia surge expressa em termos muito semelhantes pelo jesuíta, para quem os padres da Igreja não teriam na sua posse os conhecimentos necessários para interpretar as Escrituras, uma vez que largas porções da Terra só foram descobertas em tempos recentes e essas descobertas tinham relevância para a interpretação profética (Neto 2001: 85 ). Por outro lado, tal como Vieira, Mede previu um Império de natureza espiritual mas que deveria ter lugar na Terra ${ }^{1}$. Finalmente, existe uma série de coincidências entre ambos que resultam da centralidade que o livro do Apocalipse assume no pensamento de Mede e que Vieira partilhará. Entre estas estão a importância que ambos atribuem à destruição de Roma e ao número 666 e a questão da ressurreição que determinará, em última análise, o processo inquisitorial do jesuíta português.

A Clavis Apocalyptica permaneceu editada exclusivamente em latim até 1643 , altura em que o parlamento inglês ordenou a sua publicação em vernáculo, o que levaria Mede a tornar-se uma das principais referências da pulverização milenarista que emergiu nas décadas de 40 e 50 em Inglaterra. Como tal, a obra esteve desde a sua primeira publicação acessível a qualquer pessoa versada na língua latina. Contudo, fica por explicar de que forma e em que altura é que terá chegado ao jesuíta português.

É importante não esquecer que Mede atribuía também à conversão dos judeus uma importância central no esquema da instauração do Império de Cristo sobre a terra (Clouse 1969: 202). Quanto a Vieira, na opinião de António José Saraiva, "ao contrário do que é geralmente admitido, Vieira não se interessa pela questão dos cristãos-novos por simples razões conjunturais, políticas e económicas" (Saraiva 1992: 107). Na verdade, tal é confirmado pela denúncia que em 30 de outubro de 1652 foi feita na mesa da Inquisição por Manuel Álvares Carrilho, um frade de S. Bento de Avis que privou com o Padre António Vieira em Roma. Foi nos últimos meses do ano de 1649 que Vieira lhe terá confidenciado:

entendia também que Deos Nosso Senhor guardava aos hebreos, que conforme a opinião de alguns doutores rezidem tras os montes refens para algum grande

Para o caso de Vieira ver Jordán 2003: 51; para Mede, ver Firth 1979: 222. 
misterio (... ) que assim os dittos hebreos como nos mais da mesma nação que vivem entre catholicos se havião versificar, e aver effeito o reyno temporal de Christo, porquanto este não estaria ainda cumprido nem tinha havido effeito, e que se avia ainda de cumprir na ditta gente hebrea².

É bastante claro que estamos aqui em face da questão das tribos perdidas de Israel e da doutrina que afirmava que a sua descoberta seria um sinal dos últimos tempos.

O denunciante afirmou que esta conversa tivera lugar "nos últimos meses do ano de quarenta e nove”. À época, Vieira tinha vindo recentemente da Holanda onde se encontrara com Menasseh Ben Israel, uma figura de primeiro plano no panorama intelectual judaico da época (Kaplan 1989). Precisamente nessa altura existia uma polémica acerca da descoberta das tribos perdidas que empolgava os milenaristas britânicos, em particular um correspondente e amigo de Menasseh, John Dury (Van Der Wall 1988). Nesse mesmo ano de 1649, Dury escrevera a Menasseh interrogando-o acerca dos rumores que corriam sobre a eventual descoberta das tribos perdidas na América (Van Der Wall 1985: 46). Na verdade, este ano de 49 mostra todo o círculo milenarista inglês que se correspondia com Menasseh obcecado com a questão (Van Der Wall 1985: 55). Importa referir que Dury era também um homem cujo pensamento exegético resultara diretamente da influência de Joseph Mede (Popkin 1992: 96).

O milenarismo inglês era radicalmente filo-semita e Dury via no regresso dos judeus a Inglaterra simultaneamente uma condição importante para o desenvolvimento económico inglês, na mesma medida em que, dada a visão messiânica e nacionalista que atribuía ao seu país, achava que o regresso seria um sinal do advento do reino de Cristo. Para tal, começou a divulgar as obras de Menasseh em Londres, em particular as Esperanças de Israel, e colocou-o em contacto com Oliver Cromwell (Trevor-Roper 1999: 262). Em 1656 os judeus seriam readmitidos em Inglaterra, de onde tinham sido expulsos em $1290^{3}$.

Entre os séculos XVI e XVII os judeus tornaram-se um elemento fundamental no pensamento apocalíptico protestante. $\mathrm{O}$ mesmo não sucedeu no universo católico. Avihu Zakai demonstrou como a imagem do judeu se alterou radicalmente em Inglaterra durante este período (Zakai 1997). A razão última para esta importância dos judeus tinha que ver com a exegese

\footnotetext{
2 Arquivo Nacional da Torre do Tombo (doravante ANTT), Inquisição de Lisboa, Cadernos do Promotor, Livro 242, fls. 74v-75.

3 Sobre o regresso dos judeus a Inglaterra, consultar Katz 1982.
} 
tipológica. Israel era o modelo para a constituição política que se pretendia implantar em Inglaterra. A súbita emergência da literatura utópica resultante das expectativas geradas pela Revolução Inglesa era largamente marcada pelos exemplos do Antigo Testamento e pelo modelo bíblico de comunidade (Manuel 1982: 340). Para além da literatura de pendor utópico, também a teologia protestante, em particular a calvinista, via os sacramentos judaicos e cristãos como sendo essencialmente os mesmos, e atribuindo apenas à fé o modo de salvação. Assim, os judeus e os cristãos eleitos funcionavam como tipo e anti-tipo (Lewalski 1970: 1055). A este propósito é extremamente útil lembrar a polémica gerada pela proposta de Vieira acerca da recuperação das cerimónias judaicas:

da interpretação literal de David [salmo 50] consta que o Templo será reconstruído e os sacrifícios restabelecidos na época da Igreja futura na qual os judeus e os os Gentios acreditarão em Cristo Senhor (Saraiva 1992: 106).

Foi com este mundo que António Vieira contactou em Amesterdão. A 19 de Janeiro de 1649, o jesuíta Martim Leitão vinha denunciar o seu confrade António Vieira à Inquisição. Este tinha regressado havia pouco tempo da Holanda e mostrou-lhe, a ele, Martim, e a um outro padre da Companhia, Francisco Soares, dois livros que tinha trazido. De um, o denunciante não recordava o nome, do outro lembrava-se que era um livro de profecias e que Vieira lhe chamava "Vates". Francisco Soares perguntou-lhe então se aqueles livros "eram católicos" ao que lhe respondera que não. O denunciante não deixaria de mencionar que quando respondeu, Vieira sorrira "como de escárnio"4.

É impossível catalogar todas as coleções de profecias que circulavam na Europa durante o Antigo Regime. Existia uma miríade de textos, permanentemente reescritos de modo a corresponder às circunstâncias políticas de cada momento. No entanto, de entre todas as que consultei, a única que consegui identificar com este título foi um texto profético intitulado Vates anglicus, o "profeta inglês", e refere-se a um conjunto de profecias atribuídas a uma personagem mítica e que tinha larga difusão em toda a Europa: o mago Merlin $^{5}$. Como Keith Thomas demonstrou, as profecias atribuídas a Merlin foram as que conheceram maior divulgação em Inglaterra durante a guerra civil e o interregnum (Thomas 1973: 461).

ANTT, Inq. Lisboa, Promotor, livro 230, fls. 88-89.

Para a identificação do título, ver Lahdensuu 2004: 93. 
Mas Vieira não se limitou a trazer livros da Holanda. Continuou a recebê-los através de uma via privilegiada. Na verdade, parecia existir uma ordem régia para que todos os livros que chegassem à alfândega de Lisboa destinados ao Padre António Vieira não sofressem uma censura prévia da Inquisição. Foi o jesuíta Pedro de Almeida quem o revelou na mesa do Santo Ofício, no dia 16 de janeiro de 1650. Este acompanhara um outro jesuíta, Luís Pessoa, presumivelmente um homem da confiança de Vieira, para irem buscar alguns livros que tinham chegado destinados ao famoso pregador. Eis o testemunho de Almeida:

alguns dos quais [dos livros] trouxe o ditto padre Luis Pessoa para caza dizem que os trazia para o ditto padre Antonio Vieyra de quem erão, e declarou elle testemunha que ouvira dizer não lhe lembra a quem que avia ordem ou decreto de Sua Magestade para se tirarem da alfandega os livros que vinhão para o ditto padre Antonio Vieyra sem virem ao Santo Officio por virem alguns para o príncipe nosso senhor (ANTT, Inq. Lisboa, Promotor, livro 242, fl. 48).

Luís Pessoa estava consciente de que os livros eram proibidos. Pedro de Almeida provavelmente não. A dada altura, Pessoa ter-se-á dirigido a um local para comprar determinada coisa, entregando os livros a Pedro de Almeida. Nesse momento passava por ali o conde do Redondo, o qual "com curiozidade the pediu o livro para saber a matteria delle”. Quando Luís Pessoa voltou, encontrou o conde a desfolhar um dos livros. O jesuíta Pedro de Almeida nem sequer pensou que estaria a cometer uma imprudência, pelo que ficou algo espantado ao ser repreendido pelo confrade, que lhe disse que "o Padre Antonio Vieyra o avia de sentir muito, por lhe ter em conta de grande cauteloso em obrar e trazer aquelles livros" (ANTT, Inq. Lisboa, Promotor, livro 242, fl. 47). Foi nesse momento, disse, que "cresceo a elle testemunha a sospeita”. Quando interrogado acerca das características particulares dos livros em causa, a testemunha referiu um "em lingoa latina, com algumas palavras escritas em hebraico ( ... de quarto pequeno, de couza de dous dedos, encadernado em pergaminho da Flandres" (ANT, Inq. Lisboa, Promotor, livro 242, fls. 47-47v).

Quer a descrição física do livro, quer as circunstâncias cronológicas encaixam de forma perfeita levando a identificar a obra descrita como a versão latina das Esperanças de Israel de Menasseh Ben Israel. Olhando para o frontispício das edições hoje sobreviventes pode ver-se o título em caracteres hebraicos seguido da inscrição hoc est, Spes Israelis (ou seja, Esperanças de Israel). Em baixo a data, 1650 . Na verdade, o testemunho de Pedro de Almeida é de janeiro desse ano, mas sabe-se, através de uma carta de Menasseh para 
John Dury, que o livro acabou de ser impresso em dezembro de 1649, na própria oficina do autor, o qual exercia também o ofício de impressor. Nessa carta, o filósofo judeu perguntava ao seu amigo britânico se pretendia receber o exemplar encadernado ou por encadernar (Van Der Wall 1985: 58).

Daqui se podem concluir duas coisas. Primeiro, o livro foi enviado a Vieira diretamente do prelo de Menasseh, imediatamente após a sua conclusão. Segundo, Vieira fazia parte (ainda que de forma informal e distanciada) de um círculo que partilhava interesses de natureza milenarista e que tinha o seu eixo entre Londres e Amesterdão. Só assim se compreende uma tal honra concedida ao jesuíta português pelo autor/impressor. Em Londres, Dury tornou-se o grande propagador da obra, encomendando centenas de exemplares que rapidamente começou a distribuir pelos puritanos, junto dos quais se tornaria um grande sucesso editorial (Braude 1994: 1116).

Mas no testemunho de Pedro de Almeida está implícito que se tratava de mais do que um livro e que existia uma espécie de "canal aberto" para a aquisição de obras vindas do exterior. Qual a natureza dessas obras?

Em finais de outubro de 1649, no próprio quarto do rei, Vieira discutira com João Piçarro, capelão do monarca, acerca da infalibilidade papal na canonização dos santos. A denúncia não é absolutamente clara porque não permite determinar com precisão o fundo da disputa, uma vez que ambos concordavam que era de fé que o papa não podia errar nessa matéria, como nas restantes. Contudo, apesar da natureza pacífica do assunto gerou-se animosidade e a dada altura o jesuíta disse que "elle [Vieira] seguia que era de Fee que o Papa não podia errar, mas que havia muitos que dizião que não hera de Fee, e que isto mostrava por livros que mandara buscar para este effeito" (ANTT, Inq. Lisboa, Promotor, livro 242, fl. 27).

Vieira possuía livros proibidos. Isso é um facto conhecido. Ele próprio, numa carta datada de 21 de maio de 1653 e enviada ao jesuíta André Fernandes, futuro bispo eleito do Japão, faz menção a um "caixão de livros proibidos que está na livraria de S. A., os quais foram trazidos do Norte” (Hansen 2003: 197). Pede-lhe que os destrua ou que convença o rei a destruí-los e provavelmente terá sido esse o destino das obras. Mas que obras eram essas? Entre as duas já identificadas, do Vates Anglicus e das Esperanças de Menasseh, não seria de espantar que também lá se encontrasse a Clavis Apocalyptica de Joseph Mede.

A filiação do Padre António Vieira neste círculo milenarista e na sua tipologia profética, bem como a influência de Mede, exercida através desse mesmo círculo, permite uma tentativa de decifração de um dos aspetos mais desconcertantes do pensamento profético do jesuíta português. Refiro-me 
à tese de que D. João IV deveria ressuscitar. Este facto tem sido descartado como uma extravagância incompreensível (Azevedo 1984: 75). Tentarei demonstrar que não se trata de extravagância, mas sim de levar até às últimas consequências toda uma linha de raciocínio.

Antes de mais é de notar uma coincidência. A famosa carta ao bispo do Japão, onde a ideia aparece expressa, foi redigida em 1659 no Brasil. Um ano antes, em Portugal, era apreendido pelo Santo Ofício um papel que, segundo as palavras dos inquisidores Francisco Barreto e António Soares de Castro, "neste reino se publicou e espalhou". Nesta profecia é dito que no ano de 1665 "ressuscitará huma grande pessoa" e que no ano seguinte "ressuscitará outra grande pessoa” (ANTT, Inq. Lisboa, Promotor, livro 237, fl. 108). Avançando três anos, em 1661, constata-se que, em Inglaterra, os seguidores do General Thomas Harrison, um dos principais líderes do movimento da Quinta Monarquia, executado nesse ano, começaram a divulgar a ideia de que o seu líder deveria ressuscitar para cumprir as promessas frustradas do movimento (Hutton 2001: 4).

Muito provavelmente, nenhum dos três factos tem qualquer relação direta entre si. Não obstante, esta notável sincronia de acontecimentos não se deve apenas ao acaso. A meu ver, isso é devido à exegese tipológica do Apocalipse e a uma "figura" conhecida como "as duas testemunhas" (Petersen 1993). No livro do Apocalipse são mencionadas duas testemunhas que deverão morrer, jazer mortas na rua durante três dias e meio e ressuscitar. A exegese bíblica reconhece nelas as figuras de Enoch e Elias, embora outras versões incluam também Moisés (Bauckham 1998: 273). Como tal, os homens da Quinta Monarquia que seguiam Harrison afirmavam que ele deveria ressuscitar passados três dias e meio, baseando-se numa exegese figurativa que vê no oficial executado como o anti-tipo das "duas testemunhas".

Exatamente o mesmo assunto sobre que versava a profecia confiscada pela Inquisição de Lisboa, que referi acima. O trinitário frei Filipe da Rocha, encarregue pelo tribunal de qualificar as proposições contidas nesse texto, reconheceu imediatamente a alusão às "duas testemunhas". Eis o seu parecer:

3a Proposição: que nos annos de 1665 ressuscitarão dous homens grandes. Também condeno estas por erróneas e heréticas. Se estes dous homens são Henoch e Elias, como mostra a ordem das proposições, porque destes não se pode dizer que resuscitarão, pois he de Fe que não morreram. De Henoch consta estar vivo por S. Paulo (... ) De Elias consta do 4 dos Reis pois foi arrebatado vivo... (ANTT, Inq. Lisboa, Promotor, livro 237, fl. 112). 
A profecia de Lisboa e a expetativa de ressurreição por parte dos homens da Quinta Monarquia tinham uma fonte comum: a interpretação do livro do Apocalipse em chave tipológica. A coincidência cronológica também não é difícil de justificar. Estava-se a entrar na década de 60, na qual inúmeros intérpretes do texto de S. João viam como os dias do fim, a década do 666. Mas será que se pode estender esta análise ao pensamento de Vieira?

Já referi acima a importância que o Apocalipse assume na exegese de Vieira. Referi também que, tal como Mede, na sua Clavis Apocalyptica, e outros intérpretes protestantes do texto de S. João, o jesuíta identifica Roma com a imagem apocalíptica da grande prostituta da Babilónia. Durante o seu processo chegou mesmo a soltar uma crítica velada à Igreja, quando interrogado acerca das razões que levariam Deus a permitir que a Igreja fosse castigada. Disse que lhe parecia que "uma das principais razões será a pouca reformação e zelo de alguns prelados eclesiásticos, e que também será possível entrar neste numero alguns ou algum dos Sumos Pontífices no tocante àquelas cousas em que podem peccar como homens" (Muhana 1995: 87).

Foi na sessão de 8 de fevereiro de 1664 que Vieira revelou o nexo que o ligava aos dois outros casos referidos em que as "duas testemunhas" são interpretadas em chave tipológica. Nesse dia os inquisidores perguntaram-lhe em que tempo e de que modo se deveria fazer a "dita redução universal à Igreja Católica", ao que o réu respondeu:

Disse que tem lido em muitos Autores, que ensinam haver de ser esta conversão geral por meio de Henoch e Elias, depois da vinda do Anticristo, mas que segundo a doutrina de outros, e de vários lugares da Sagrada Escritura que em sua defesa alegará, lhe parece (mui) provável poder ser a dita conversão universal antes da vinda do Anticristo, por meio dos pregadores evangélicos, para o que poderá ajudar muito o rei de Portugal que então for (Muhana 1995: 80).

A questão que aqui se coloca é só uma e era polémica junto dos exegetas do Apocalipse: como identificar as figuras das "duas testemunhas". O jesuíta rejeita a interpretação figurativa de Enoch e Elias, colocando no seu lugar os pregadores evangélicos, por um lado, e o "rei de Portugal que então for", por outro. Ora, o réu estava a jogar à defesa ao falar no rei "que então for". Para Vieira seria sempre D. João IV. Ele próprio, em vários passos do processo o deixa a entender, não de forma explícita, mas deixando no ar a possibilidade. Segundo as suas próprias palavras, o réu tinha "a dita ressurreição e as ditas duas proposições por moralmente prováveis” (Muhana 1995: 54). 
$\mathrm{Na}$ verdade, ao identificar as duas testemunhas com a dualidade entre pregadores da Igreja e rei de Portugal, Vieira estava apenas a corporizar uma ideia que aparece de forma insistente no seu pensamento profético e que tinha raízes profundas na Europa (Weinstein 1970). Refiro-me à ideia de uma autoridade dupla, secular e religiosa. Um "papa angélico" e um "imperador dos últimos dias" seriam os dois instrumentos da regeneração do mundo. Segundo as palavras de um dos mais reputados especialistas do pensamento de António Vieira, Raymond Cantel, no sistema do jesuíta português "os homens não verão a Cristo. Este regenerará o seu império por intermediário de dois representantes escolhidos desde a eternidade. Um será o Papa e o outro o rei de Portugal" (Cantel 1960: 136).

Contudo, para além da influência externa, existe uma razão interna à sua condição de jesuíta que nos ajuda a compreender o pensamento de Vieira. É comum pensar-se que o famoso processo de Vieira na Inquisição foi o primeiro e único ${ }^{6}$. Não obstante, cerca de dez anos antes do início do seu processo, a 21 de julho de 1663, iniciara-se um outro que levava o seu nome na capa, juntamente com a de um outro jesuíta, Inácio Mascarenhas (ANTT, Inq. Lisboa, proc. 10652).

$\mathrm{O}$ processo teve origem em outubro de 1652, quando o inaciano se preparava já para atravessar o Atlântico. Como tal, seria Mascarenhas a responder na mesa do tribunal. Na base de tudo esteve uma denúncia de João Piçarro, o capelão do rei. Piçarro encontrava-se no quarto do príncipe juntamente com os dois jesuítas e com Sebastião César de Meneses, membro do conselho do rei, do conselho geral da Inquisição e bispo eleito de Coimbra ${ }^{7}$. Num dado momento, o capelão lamentou a sorte de um inglês protestante que fora recentemente enforcado e levado a queimar para a Igreja de S. Paulo. Piçarro tinha-se esforçado, juntamente com certa "pessoa de letras", a que o inglês renunciasse à fé protestante. Os esforços foram em vão e o capelão lamentava a sorte daquela alma, que agora estaria no inferno. Inácio Mascarenhas tomou a dianteira. Chamou "temerário" ao capelão por ter proferido aquela afirmação, tentando persuadi-lo que

o homem se poderia salvar seguindo sempre sua seita de seos erros e acabando nelles porquanto o homem poderia estar sempre firme entendendo que a dita sua seita era a verdadeira, e que só com estar baptizado e não tendo feito peccado mortal bastaria para se salvar.

\footnotetext{
Sobre as causas do processo ver Paiva 2011.

A denúncia de Piçarro está em ANTT, Inq. Lisboa, proc. 10652, fl. 8 e ss.
} 
O capelão respondeu-lhe que não se podia sequer alegar ignorância neste caso, uma vez que lhe foram explicados os mistérios da fé católica, que ele, o inglês, obstinadamente recusou por falsos. Mascarenhas não desarmou:

Ainda no caso que hum semelhante herege se reduzisse à Fee crendo firmemente nella e depois o ditto tornasse aos primeiros erros tendo para si que quem o reduzira a Fee o enganara e que os motivos que lhe apontara eram falsos ainda antes persuadido que a dita sua seita era certa, apegando se a ella firmemente sem duvidar, se podia salvar assim como no primeiro cazo, dando por rezão... a obrigação de seguir a consciência errónea (ANTT, Inq. Lisboa, proc. 10652 , fls. $8 \mathrm{v}-9$ ).

O inquisidor anotou na margem: "obrigação de seguir a consciência errónea”. Mascarenhas só viria a ser chamado à mesa do Santo Ofício em fevereiro de 1653. Entretanto, em novembro do ano anterior, poucas semanas após a altercação com Piçarro, já o seu confrade António Vieira tinha seguido rumo ao Brasil. No dia 18 de fevereiro de 1653 Inácio Mascarenhas encetou, de forma convicta e com uma erudição teológica notável, a defesa da consciência individual como critério último da salvação, invocando a autoridade de S. Tomás de Aquino. Por fim disse que precisava de mais tempo e, por isso, pedia que lhe deixassem trazer os fundamentos da sua posição por escrito ${ }^{8}$.

É difícil determinar as razões que levaram o Santo Ofício a demorar cerca de quatro meses para chamar Mascarenhas à mesa do tribunal. Inusitada foi, também, a duração do processo, que se prolongou por seis anos. Todavia, quando se olha para o documento percebe-se que a questão não era tão óbvia como poderia parecer. A maior parte da documentação constante do volume é constituída por pareceres de qualificadores, nos quais se encontram vertidos um legalismo e uma minúcia excecionais. Só em 1658, de forma a dissipar dúvidas, a Inquisição de Lisboa escreveu para Roma, o que demonstra bem que a dúvida se tinha instalado.

A 9 de março de 1658, o cardeal Barberini, da Sagrada Congregação do Santo Ofício, escrevia para Lisboa uma carta em que a proposição era censurada para além de qualquer dúvida (ANTT, Inq. Lisboa, proc. 10652, fl. 136). Em agosto eram chamados à mesa, para abjurarem dos seus "erros", Inácio Mascarenhas, vários qualificadores do Santo Ofício que tinham avaliado a proposição como lícita e três jesuítas, entre os quais o próprio provincial da Companhia, Manuel Tinoco?.

\footnotetext{
A sessão de Mascarenhas encontra-se nos fls. 45 e ss.

As abjurações encontram-se nos fls. 133 e ss.
} 
Mas já antes, em 1649, Vieira se tinha exposto publicamente em relação a este assunto, tendo sido alvo de denúncia. O jesuíta tinha acabado de chegar da Holanda e dirigira-se a Alcântara para falar com o rei. Vieira surge opulento, trajando à civil, "vestido de cinto com espada e luvas guarnecidas de ouro". $\mathrm{O}$ denunciante não o conhecia, mas o homem que o acompanhava, o inevitável João Piçarro, disse-lhe "que era o padre Antonio Vieira, que naquella ocazião tinha vindo das partes do Norte aonde sua magestade o mandara" (ANTT, Inq. Lisboa, Promotor, livro 242, fl. 18 e ss).

Segundo o testemunho de Pedro Álvares, Piçarro estava absorto a ler um breviário em voz alta quando o jesuíta o interpelou. Disse-lhe que aquilo que estava a ler não era verdade. Piçarro argumentou, compreensivelmente, que deveria ser verdade porque estava escrito no breviário. Vieira disse então:

... se hum homem fosse criado por seus pays em qualquer das seitas contrarias a Nossa Santa Fee catholica e depois de doutrinado nella seguisse tendo-a por boa ainda que depois alcançasse o conhecimento de Nossa Santa Fee, se contudo se não soubesse determinar em qual dellas havia de alcançar a salvação e nesta duvida recorresse com a consideração a Deos e dissesse que fosse servido encaminhallo no que dizia seguir para se salvar que era o seu principal intento, $\mathrm{e}$ sobre isto seguisse e continuasse na crença da ditta seita em que se criara, sendo sempre o intento de abraçar a salvação, bastaria para a alcançar.

A dada altura tirou as luvas dizendo ao seu interlocutor:

... que culpa teria elle João Piçarro se querendo dar-lhe elle ditto padre a melhor das dittas luvas e procurando a esse fim alcançar qual dellas o era, contudo lhe desse aquella que tivesse alguma macula oculta ou falha ...

O inquisidor anotou na margem: "comparação das luvas" (ANTT, Inq. Lisboa, promotor, livro 242, fl. 20).

É de salientar que a liberdade de consciência estava, nessa precisa altura, a ser um dos pontos mais discutidos em Inglaterra, onde a vida religiosa do país se estava a pulverizar em seitas promotoras de anticlericalismo e da valorização de uma interioridade radical e até mesmo anárquica (Zagorin 2003: 188; Haller 1963; Davis 1992).

No que diz respeito ao pensamento jesuítico e à sua relação com a tolerância encontramo-nos face a uma questão semelhante à da exegese do Apocalipse. Tal como os atrás mencionados jesuítas Cornelius ou Ribera criaram uma interpretação que viria a florescer no universo protestante, também aqui vemos diversos jesuítas a opinar sobre um assunto que ocupava, à época, o 
centro da discussão em terras britânicas, no contexto da guerra civil. Um grande especialista da espiritualidade jesuíta, John O’Malley, viu nesta um nexo de ligação com a espiritualidade protestante por via da importância que ambas atribuíam à figura de S. Paulo (O’Malley 1988: 19). Seja como for, é necessário não perder de vista que na abjuração do processo Vieira/Mascarenhas estavam, para além do mesmo Mascarenhas, outros três jesuítas e um deles era o próprio provincial.

Como sublinhou Adriano Prosperi, esta abertura de espírito seria sempre inevitável numa instituição que foi fundada por um homem que experimentou pessoalmente a repressão inquisitorial e que tinha uma assumida vocação universalista (Prosperi 1994: 194-95). A autoridade de referência dos jesuítas nesta matéria era S. Tomás de Aquino, cuja ética se funda na defesa radical da consciência individual. Ao contrário da ética franciscana, na qual deveria prevalecer o respeito à lei divina, fundado no amor por Deus, $S$. Tomás dizia que mesmo quando a consciência é errónea deve ser seguida pois o bem visado por uma ação não é o bem em si, mas sim o bem enquanto apresentado a mim pela minha própria razão (Filho 2008: 180-81; Chenu 1991: 25-55).

A revolução inglesa libertou forças que geraram um pluralismo religioso irreversível, mesmo depois da restauração monárquica. A proliferação das seitas tornou impossível estabelecer uma ortodoxia que funcionasse como âncora do pensamento religioso. A controvérsia acerca da separação entre Igreja e Estado estava em voga e vinha já sendo discutida ainda antes da eclosão da guerra civil. Um bom exemplo disso mesmo foi a polémica entre John Cotton e Roger Williams, na década de 30, na colónia britânica da Nova Inglaterra. Cotton defendia que a pessoa que persistisse no erro depois de lhe ter sido mostrada a verdade era culpada, não de "consciência errónea", mas de pecado contra a consciência. Williams discordava e defendia o oposto. Para além da coincidência ideológica e terminológica com o caso Vieira/ /Mascarenhas, é relevante notar que Roger Williams utilizou um esquema de interpretação tipológica das Escrituras para justificar a sua posição (Trevor-Roper 1999: 201) $)^{10}$.

Mas os fios que tecem o triângulo formado por Vieira, a ideia de tolerância e o milenarismo inglês não se esgotam aqui. Com efeito, Richard Popkin chamou a atenção para uma situação aparentemente paradoxal: foi das duas forças mais extremadas em relação à religião que saíram as primeiras reivin-

10 Um estudo bastante desenvolvido acerca da interpretação tipológica utilizada nesta controvérsia é Bercovitch 1967. 
dicações de tolerância religiosa. Referia-se ao ceticismo religioso e ao milenarismo (Popkin 1998). No seu texto, Popkin associa, entre vários outros, Vieira e John Dury, dois dos homens a quem Menasseh enviou um exemplar das Esperanças de Israel. Dury tinha um projeto de união de todas as igrejas cristãs envolvidas por um cristianismo para além de credos e doutrinas particulares (Popkin 1998: 245). Estamos aqui no domínio da utopia religiosa.

Existem, certamente, razões para o súbito desenvolvimento da utopia como género literário nos séculos XVI e XVII, de que são exemplos a Oceana de Harrington ou a Macaria de Samuel Hartlib. Uma razão evidente terá sido o fascínio da descoberta de novos mundos e novas formas de sociedades humanas. Contudo, seria demasiado simplista ficar por aí. De facto, a desagregação das organizações tradicionais e a paralela consolidação dos Estados nacionais, com uma inusitada extensão de poderes, rápido crescimento da maquinaria e desenvolvimento da administração, fizeram com que fosse o Estado a posicionar-se como o único obstáculo a uma situação política e religiosamente fragmentada e caótica (Eliav-Feldon 1982: 128).

Embora seja frequentemente associado à ideia de utopia, a verdade é que o Padre António Vieira nunca produziu um escrito que se possa designar, com propriedade, utópico. Da descrição política, legislativa ou social de uma sociedade ideal nada se lhe conhece. Confiava, certamente, no carácter autorregenerador do reino de Cristo implantado na terra.

Os movimentos revolucionários em Inglaterra tiveram uma importância excecional e um impacto enorme na Europa. Pela primeira vez um povo depunha e executava um monarca que se julgava investido de poder divino. Dois anos antes da execução do rei, em 1647, quando a situação política estava profundamente agitada, Vieira teve uma breve estadia em Inglaterra. Lúcio de Azevedo mostra estranheza porque:

nesses poucos dias que passou em Inglaterra este homem tão perspicaz parece surdo ao rumor dos acontecimentos que então agitavam o país ... o rei prisioneiro, o exército constituído em poder do Estado, a nação convulsa, e uma espécie de novo judaísmo, na exuberância das aplicações bíblicas, a triunfar com a rebelião (Azevedo 1992: 101-102).

Não creio que este silêncio se deva a desinteresse, mas a uma prudente omissão. Foram muito bem dissimuladas todas as influências que tenho vindo a referir e é significativo e compreensível que Vieira não mencionasse autores protestantes no seu processo. O próprio Menasseh é aí mencionado de uma 
forma seca e distante, como se se tivesse tratado de um simples encontro ocasional (Muhana 1995: 93).

As consequências dos acontecimentos ingleses no profetismo português ultrapassam a questão do Quinto Império e do Padre António Vieira. Os arquivos da Inquisição fornecem-nos exemplos que ilustram essa influência. Um dos mais interessantes e curiosos é o do profeta e homicida Francisco de Mendonça, frade do convento cartuxo de Laveiras, e dos seus dois seguidores Bruno do Espírito Santo e António Serrão. O caso decorreu em 1651. Francisco de Mendonça alimentava a convicção de que Lisboa deveria ser cabeça do mundo e que ele, Mendonça, estava destinado a fazer uma reforma da qual resultaria grande felicidade para a humanidade, criando a "igreja de Sião" onde reinaria a paz e a felicidade ${ }^{11}$. Deveria ser acompanhado nesta tarefa por um outro frade, Bruno do Espírito Santo, que segundo ele estaria destinado ao pontificado (ANTT, Inq. Lisboa, proc. 788, fl. 44). Contudo, a conduta sexual de Mendonça era mais do que reprovável. Antes de estar preso no seu convento, devido a um homicídio para o qual nem sequer tinha razões que o justificassem (que ele justificou porque "Deus lhe dissera [para o fazer] e Ele era o Senhor das Vidas"), Mendonça escrevia cartas a "mulheres mundanas", que na sua perspetiva muito particular considerava "anjos" (ANTT, Inq. Lisboa, proc. 788, fl. 18). Tudo isto estava, segundo o nosso profeta, aprovado por Deus. Este visionário dividia o mundo em duas categorias de homens, os que estavam destinados à salvação (a quem designava por predestinados) e os outros. Nesta ótica, qualquer conduta era aceitável e agradável a Deus. Uma só coisa era inadmissível e pecaminosa: ignorar a sua condição de predestinado ${ }^{12}$.

Fundado neste suporte ideológico, o seu discípulo Bruno do Espírito Santo desenvolveu uma relação de carácter homossexual com um terceiro frade cartuxo, António Serrão. Bruno convenceu Serrão de que aquelas ações eram agradáveis a Deus, acrescentando ainda que

como havia de ser Papa e governar a matéria dos matrimónios, importava que cousa era a semente delle confitente [de António Serrão]... e que das outras vezes que tinha visto a semente delle confitente lhe não parecera tão substancial como a delle Dom Bruno... (ANTT, Inq. Lisboa, proc. 3997, fl. 49v ).

11 "Que na ditta igreja de Sião averia muitas felicidades e santidades, e que avia Deus de seccar os mares e criar nelles reynos” (ANTT, Inq. Lisboa, proc. 788, fl. 46).

12 "Que os predestinados que soubesem que o erão ficavam eximidos da ley e não peccavão posto que fizessem tudo o quizessem de bem e de mal” (ANTT, Inq. Lisboa, proc. 788, fl. 34). 
Por seu lado, Serrão começou a ter sonhos que parecem ligar a questão da semente humana à ideia escatológica de uma renovação do mundo. Dois deles são bastante reveladores:

Sonhou elle confitente huma vez que vira hum clérigo de Lisboa seu conhecido e que estava em trajos de mulher e que estava prenhe, e dando conta do ditto sonho, como sonho e não revelação ou visão, ao ditto Dom Bruno, este o explicou dizendo que aquillo poderia ser visão do Padre Eterno, e que com aquella representação de prenhez dar a entender que erão lícitos aquelles actos carnaes (ANTT, Inq. Lisboa, proc. 3997, fl. 50).

É difícil determinar qual a influência que esta justificação de Dom Bruno terá tido na cabeça de António Serrão. $O$ facto é que este voltaria a sonhar:

Vira um menino com quem estava fallando, o qual disse a elle confitente que estava prenhe, elle confitente lhe perguntou no mesmo sonho de quem o estava, e o ditto menino respondera - de ti - e que entendera no mesmo sonho que era o menino Jesus mas que em tal sonho não creu (ANTT, Inq. Lisboa, proc. 3997, fls. 50-50v).

É digna de nota a menção à predestinação numa altura em que as disputas confessionais dilaceravam a Europa. A negação do livre arbítrio é extrema, aproximando Mendonça (que parece ser o doutrinador) das teses protestantes, especialmente calvinistas: "brutos animais, não têm liberdade para fazer o que fazem, movidos por Deus, assim são os homens" (ANTT, Inq. Lisboa, proc. 788 , fl. 12, segunda numeração). Paralelamente afirmou que era "contra o que a Igreja tinha” e negou a existência do purgatório e do inferno (ANTT, Inq. Lisboa, proc. 788, fl. 34). Na realidade, esta última conclusão era apenas uma consequência lógica das teses avançadas atrás.

Ia já longa nesta época a história europeia do antinomianismo de fundo místico (McGinn 2005: 57). Este define-se como uma reação contra a norma, desembocando num relativismo moral e apenas reconhecendo a consciência individual como fonte de autoridade. Mas apesar de longa na Europa era inexistente em Portugal, tal como o fora em Inglaterra, local onde conheceu, precisamente neste período, uma proliferação resultante da multiplicação de seitas. Há uma coincidência que não pode deixar de se notar. Arthur Morton, grande estudioso dos ranters, uma seita mística acusada de diversos desvios, desde homicídios a licenciosidade sexual, diz que foi precisamente nos anos finais da guerra civil e subsequentes que o antinomianismo apareceu subitamente em Inglaterra, tendo resultado, por um lado, da ideia 
de que estava iminente uma nova era e, por outro, da libertação da antiga submissão (Morton 1979: 79). Na realidade, a decapitação de Carlos I, que pôs fim ao conflito, aconteceu em 1649, dois anos antes de a Inquisição começar a interessar-se por Francisco Mendonça.

$\mathrm{Na}$ origem deste antinomianismo estava a mística de raiz neoplatónica. Esta implicava a ideia da existência de uma centelha de divindade no interior da alma humana. Recolhendo-se para o interior de si próprio, o homem deveria reconhecer a sua própria origem divina. Jogando com paradoxos e com o princípio de que não pode haver afirmação sem a ideia de negação, postulava-se que Deus não poderia existir apenas para si, mas deveria manifestar-se no mundo, regressando a si de forma auto-consciente. O quietismo, providencialismo e auto-divinização que daí resultam levavam, frequentemente, a uma desvalorização da conduta moral. Desta forma de misticismo nasceram em Inglaterra, entre outros movimentos mais ou menos mitigados, duas seitas: os ranters e os quakers. A causa próxima desta situação terá sido o interesse que se começou subitamente a revelar em Inglaterra, a partir de 1640, pela obra de dois místicos neoplatónicos, Nicolau de Cusa e Jacob Boheme. Este último, em particular, teve uma importância decisiva ${ }^{13}$.

Ora, o fundo filosófico de Francisco de Mendonça é claramente platónico. A ideia de um Deus que se afirma por negação e que necessita de mergulhar na criação para se tornar consciente do seu ser é clara:

que Deus Nosso Senhor no primeiro instante da eternidade estava como pasmado e arrobado, vivo mas sem discursus e sem obra alguma, e que no segundo instante tornara sobre sy e se vira Deos incriado, e começara a tratar de sua conservação, e de crear as cousas (ANTT, Inq. Lisboa, proc. 788, fl. 71, segunda numeração).

Depois surge a ideia consequente da auto-divinização e da centelha do espírito de Deus na alma:

que os predestinados não eram criados como as outras criaturas, mas como hum Deus multiplicado derivado do Spiritu de Deos, uns imediatamente e os outros destes, e que elle Dom Francisco era dos predestinados immediatamente derivado de Deos, e que conhecia outros predestinados em differente grau ${ }^{14}$.

13 Sobre a importância de Boheme no pensamento de George Fox, fundador dos quakers ver Hudson 1943: 179. As primeiras traduções de Boheme e Cusa, acolhidas entusiasticamente, ocorreram precisamente durante o período de guerra civil (Manuel 1982: 352).

14 ANTT, Inq. Lisboa, proc. 788, fl. 30, depoimento de António Serrão a 14 de junho de 1650. 
A sociedade portuguesa era severamente policiada, o que levanta a questão de como é que se terá processado o contágio, de Inglaterra até Portugal. $\mathrm{Na}$ verdade, a vigilância existia, mas a dissidência também e esta tentava explorar as falhas do sistema. Vimos um exemplo disso mesmo na ordem régia para isentar de censura inquisitorial os livros que vinham para António Vieira. Um outro exemplo é o do processo da inglesa Ana Gargim.

Ana era uma missionária de trinta anos da seita dos quakers, precisamente um dos grupos resultantes da doutrina de "iluminação interior" de fundo neoplatónico. Embarcou em 1656 no porto de Plymouth com destino a Lisboa. O seu propósito era simples e ingénuo: pregar a sua fé em Portugal.

Os quakers tinham surgido em Inglaterra apenas quatro anos antes e tiveram uma difusão alargada e imediata. Desempenharam um papel importante ao absorver e moderar as tendências de antinomianismo radical existente no grupo dos ranters, nomeadamente o seu materialismo e radicalismo agressivo (Morton 1979, 18). Apesar de tudo, os quakers eram frequentemente confundidos com aqueles e tornavam-se alvo de acusações de promiscuidade sexual e depravação. É possível que a semelhança doutrinal entre ambos os grupos tivesse gerado a confusão. $\mathrm{O}$ facto é que os quakers eram um movimento ligado também à exegese bíblica e ao milenarismo e tinham a característica de conceder um grau extraordinário de autonomia às mulheres (Mack 1982: $24)^{15}$. E isto explica em grande medida o aparecimento de Ana Gargim.

O padre Carlos do Rio, provedor do colégio dos ingleses de S. Pedro e S. Paulo, terá compreendido o perigo da vinda de Ana a Portugal dizendo que se a ditta mulher ficar neste reyno a entender a lingoa delle seria muito prejudicial porquanto na sua seita se permitem muitas liberdades que se acomodam com a natureza e seriam fáceis de abraçar-se (ANTT, Inq. Lisboa, proc. 13011, fl. 7v).

Fora precisamente isso que já acontecera relativamente a Francisco de Mendonça.

A seita dos quakers, "que quer dizer trementes, seita que novamente [recentemente] se introduziu em Inglaterra”, no dizer de Carlos do Rio, praticava um proselitismo vigoroso. Ao ser interrogada, Ana Gargim expôs de forma genérica aquilo que já foi referido atrás. A dada altura disse na mesa do tribunal que na dita seita não há preceito que obrigue a pecado mortal, porque o spirito guia a não peccar, e que so peccaria aquelle que não seguir aquelle ditame do spirito (ANTT, Inq. Lisboa, proc. 13011, fl. 20).

15 Sobre a exegese bíblica e o milenarismo de George Fox, fundador da seita ver Delumeau 1997: 289. 
Mas o processo desta mulher fornece algumas pistas interessantes para aferir do nível de policiamento religioso que era praticado, bem como das respetivas vulnerabilidades. A chegada perturbou a comunidade inglesa de Lisboa, que a obrigou a permanecer no barco enquanto estivesse na cidade, tentando (e acabando por conseguir) que ela ficasse aí retida. Carlos do Rio afirma que

os hereges ingleses moradores neste reyno se sentirião muyto da liberdade da ditta mulher por entenderem que do escândalo que ella causaria poderia nascer alguma perturbação nas pazes que de presente se tratavão.

Existia, portanto, uma comunidade de "hereges" a viver em Lisboa e reconhecidos como tal. Um desses hereges serviu mesmo de intérprete entre Carlos do Rio e Ana Gargim. Tratava-se de "hum rapaz vestido de preto, que dizia ser inglês e herege e falava muito bem portugues" (ANTT, Inq. Lisboa, proc. 13011, fl. 15).

Na verdade, desde 1654 que Portugal se vira forçado a ceder às duras exigências da República Inglesa, que exigiu isenção da jurisdição inquisitorial, a possibilidade de utilizar as suas bíblias, exercer atos de culto protestante em casas ou a bordo e ainda que os ingleses protestantes tivessem um local assinalado como cemitério privativo (Prestage 1928: 145). Na altura em que decorreu o caso de Ana Gargim havia negociações para a ratificação do tratado e a comunidade inglesa estava receosa, naturalmente, que a vinda desta mulher viesse perturbar uma situação que lhes permitia imensas vantagens.

Temos, portanto, uma comunidade solidamente estabelecida e interessada no comércio, constituída em larga medida por protestantes e, certamente (a avaliar pela amostra do que se passava em Inglaterra), vários milenaristas, com uma ampla margem de manobra para atuar em Portugal. E esta situação pode muito bem explicar um caso como o de Francisco de Mendonça.

Sucede assim que a sociedade portuguesa não era tão estanque quanto tantas vezes se supõe. Um dos paradoxos resultantes dessa fluidez de ideias foi o facto de a formação de um mito nacional e "nacionalista", que perdurou por séculos, ter sido construído com matéria-prima importada. Por outro lado, essa fluidez de ideias não se restringia às camadas letradas. Um bom exemplo disso é a "profecia da ressurreição" que mencionei atrás, um papel que se destinava a circular pela população, permanentemente recopiado e adaptado às circunstâncias. Se as subtilezas da exegese bíblica escapavam de todo ao homem comum, já as predições daí resultantes encontravam uma calorosa receção e divulgação. O mesmo se passaria com o antinomianismo. 


\section{Bibliografia}

APPLEBY, Joyce Oldham (1980). Economic thought and ideology in seventeenth-century England. Princeton: University Press.

ARMOGATHE, J.-R. (2001). "Per Annos Mille: Cornelius a Lapide and the interpretation of Revelation 20:2-8”, in Karl A. Kottman (ed.), Millenarianism and messianism in Early Modern European culture. Vol. 2: Catholic millenarianism: from Savonarola to the Abbé Grégoire. Dordrecht, Boston, London: Kluwer, 45-51.

AUERBACH, Erich (1994). Figura. Paris: Belin.

AZEVEDO, José Lúcio de (1984). A evolução do sebastianismo. Lisboa: Presença.

AZEVEDO, José Lúcio de (1992). História de António Vieira. Lisboa: Clássica Editora.

BAUCKHAM, Richard (1998). The climax of prophecy. Studies in the Book of Revelation. Edinburgh: T\&T Clark.

BERCOVITCH, Sacvan (1967). “Typology in Puritan New England: the Williams-Cotton controversy reassessed”, American Quarterly, 19, 166-191.

BOXER, Charles R. (1977). O império colonial português. Lisboa: Edições 70.

BRAUDE, Benjamin (1994). "Les contes persans de Menasseh Bem Israel. Polémique, apologétique et dissimulation à Amsterdam au XVII ${ }^{e}$ siècle”, Annales H.S.S., 5, 1107-1138.

CAÑIZARES-ESGUERRA, Jorge (2007). "Entangled histories: borderland historiographies in new clothes?", American Historical Review, 112, 787-799.

CANTEL, Raymond (1960). Prophétisme et messianisme dans l'œuvre d’Antonio Vieira. Paris: Ediciones Hispano-Americanas.

CARVALHO, José Adriano de Freitas (2002). "A difusão da Apocalypsis Nova atribuída ao beato Amadeu da Silva no contexto cultural português da primeira metade do século XVII", Revista da Faculdade de Letras do Porto, 19, 5-40.

CHENU, Marie-Dominique (1991). Il risveglio della coscienza nella civiltà medievale. Milano: Jaca Book.

CLOUSE, Robert G. (1969). “Johann Heinrich Alsted and English millennialism”, Harvard Theological Review, 62, 189-207.

DAVIS, J.C. (1992). "Religion and the struggle for freedom in the English Revolution”, The Historical Journal, 35, 507-530.

DELUMEAU, Jean (1997). Mil anos de felicidade. Lisboa: Terramar.

ELIAV-FELDON, M. (1982). Realistic utopias. The ideal imaginary societies of the Renaissance. Oxford: Clarendon Press.

FILHO, Juvenal Savian (2008). "O tomismo e a ética: uma ética da consciência e da liberdade”, Bioethikos, 2, 177-184.

FIRTH, Katharine R. (1979). The apocalyptic tradition in Reformation England. Oxford: University Press. 
HALLER, William (1963). Liberty and Reformation in the Puritan Revolution. New York, London: Columbia University Press.

HANSEN, João Adolfo (org.) (2003). António Vieira. Cartas do Brasil: 1626-1697, Estado do Brasil e Estado do Maranhão e Grão-Pará. S. Paulo: Hedra.

HUDSON, Winthrop S. (1943). “Gerrard Winstanley and the early quakers”, Church History, $12,177-194$.

HUTTON, S. (2001). “The appropriation of Joseph Mede: millenarianism in the 1640's" in James Force, Richard Popkin (ed.), Millenarianism and messianism in early modern culture. Vol. 3. The millenarian turn. Dordrecht: Kluwer, 1-13.

JORDÁN, María V. (2003). “The empire of the future and the chosen people: Father António Vieira and the prophetic tradition in the Hispanic world”, Luso-Brazilian Review, 40, 45-57.

KAPLAN, Yosef et al. (1989). Menasseh Ben Israel and his world. Leiden: E. J. Brill.

KATZ, David S. (1982). Philo-semitism and the readmission of the jews to England, 16031655. Oxford: Clarendon Press.

LAHDENSUU, Laura (2004). "Predicting History: Merlin's prophecies in Italian XII ${ }^{\text {th }}-\mathrm{X}$ $\mathrm{V}^{\text {th }}$ century chronicles", in Erik Kooper (ed.), The Medieval Chronicle III. Proceedings of the $3^{\text {rd }}$ International Conference on the Medieval Chronicle. Amsterdam: Rodopi, 93-100.

LEWALSKI, Barbara K. (1970). Samson Agonistes and the Tragedy of the Apocalypse, PMLA, 85, 1050-1062.

LUBAC, Henri de (1959). Exégèse médiévale. Les quatre sens de l'Écriture. Seconde Partie. Vol. 1. Paris: Aubier.

LUBAC, Henri de (1981). La postériorité spirituelle de Joachim de Flore. I: De Joachim à Schelling. Paris: Lethielleux.

MACK, Phyllis (1982). "Women as prophets during the English civil war", Feminist Studies, $8,17-45$.

MANUEL, Frank E.; MANUEL, Fritzie P. (1982). Utopian thought in the Western world. Oxford: Basil Blackwell.

MAZZEO, Joseph A. (1954). "Universal Analogy and the Culture of the Renaissance”, Journal of the History of Ideas, 15, 299-304.

MCGINN, Bernard (2005). The harvest of mysticism in Medieval Germany (1300-1500). New York: Herder \& Herder.

MORTON, A. L. (1979). The world for the ranters. Religious radicalism in the English Revolution. London: Lawrence \& Wishart.

MUHANA, Adma (1995). Os autos do processo de Vieira na Inquisição. São Paulo: UNESP.

MULSOW, M. (2001). "Who was the author of the Clavis Apocalyptica of 1651? Millenarianism and prophecy between Silesian mysticism and the Hartlib Circle”, in John Christian Laursen, Richard H. Popkin (ed.), Millenarianism and nessianism in Early Modern 
culture. Vol. IV: Continental millenarians: protestants, catholics, heretics. Dordrecht: Kluiwer, 57-75.

NETO, J. R. Maia (2001). "Vieira's epistemology of History”, in Karl A. Kottman (ed.), Millenarianism and messianism in Early Modern European culture. Vol. 2: Catholic millenarianism: from Savonarola to the Abbé Grégoire. Dordrecht, Boston, London: Kluwer, 79-89.

O’MALLEY, John (1968). Giles of Viterbo on Church and Reform. A study in Renaissance thought. Leiden: E. J. Brill.

O’MALLEY, John (1988). "Early Jesuit spirituality: Spain and Italy”, in Louis Dupré, Don E. Saliers (ed.), Christian spirituality: Post-Reformation and Modern. New York: SCM Press, 3-27.

PAIVA, José Pedro (2011). “Revisitar o processo inquisitorial do Padre António Vieira”. Lusitania Sacra, 23, 151-168.

PETERSEN, Rodney L. (1993). Preaching in the last days: the theme of "Two Witnesses" in the sixteenth and seventeenth centuries. Oxford: University Press.

POPKIN, Richard (1992). The third force in seventeenth-century thought. Leiden: Brill.

POPKIN, Richard (1998). "Scepticism about religion and millenarian dogmatism: two sources of toleration in the seventeenth century", in John Christian Laursen, Cary J. Nederman (ed.), Beyond the persecuting society. Religious toleration before the Enlightenment. Philadelphia: University of Pennsylvania Press, 232-250.

PRESTAGE, Edgar (1928). As relações diplomáticas de Portugal com a França, Inglaterra e Holanda de 1640 a 1668. Coimbra: Imprensa da Universidade.

PROSPERI, Adriano (1994). "L'inquisitore come confessore”, in Paolo Prodi (dir.), Disciplina del corpo, disciplina dell'anima e disciplina della società tra medioevo ed età moderna. Bologna: Il Mulino, 187-224.

REEVES, Marjorie (1991). "Cardinal Egidio of Viterbo and the Abbot Joachim”, in Gian Luca Potestá (dir.), Il profetismo gioachimita tra Quattrocento e Cinquecento. Atti del III congresso internazionali di studi gioachimiti. Genova: Marietti, 139-155.

REEVES, Marjorie (1993). The influence of prophecy in the later Middle Ages. A study in Joachimism. Notre Dame, London: University of Notre Dame Press.

SARAIVA, António José (1992). “António Vieira, Menasseh Ben Israel e o Quinto Império”, in História e Utopia. Estudos sobre Vieira. Lisboa: Instituto de Cultura e Língua Portuguesa, 75-107.

SWAIN, Joseph Ward (1940). "The theory of the four monarchies opposition under the Roman Empire”, Classical Philology, 35, 1-21.

THOMAS, Keith (1973). Religion and the decline of magic. Studies in popular beliefs in sixteenth and seventeenth century England. Harmondsworth: Penguin Books.

TREVOR-ROPER, Hugh (1999). The crisis of the seventeenth century. Religion, the Reformation and social change. Indianapolis: Liberty Fund. 
VAN DER WALL, Ernestine (1985). “Three letters by Menasseh Bem Israel to John Durie”, Nederlands Archief voor Kerkgeschiedenis, 65, 46-63.

VAN DER WALL, Ernestine (1988). “The Amsterdam millenarian Petrus Serrarius (16001669) and the Anglo-Dutch circle of philo-judaists”, in J. Van Den Berg, Ernestine Van der Wall (ed.), Jewish-Christian relations in the seventeenth century. Studies and documents. Dordrecht: Kluwer, 1988, 73-94.

WEINSTEIN, Donald (1970). Savonarola and Florence: prophecy and patriotism in the Renaissance. Princeton: University Press.

ZAGORIN, Perez (2003). How the idea of religious toleration came to the West. Princeton: University Press.

ZAKAI, Avihu (1997). "From judgement to salvation: the image of the jews in the English Renaissance", The Westminster Theological Journal, 59, 213-230. 